\title{
Eurynothrips Bagnall (Thysanoptera, Phlaeothripinae): a rare and long-lost Australian genus, with one new gall-inducing species
}

\author{
LAURENCE A. MOUND ${ }^{1} \&$ DESLEY J. TREE ${ }^{2}$ \\ ${ }^{1}$ Australian National Insect Collection CSIRO, PO Box 1700, Canberra, ACT 2601 \\ झ"laurence.mound@csiro.au; $\odot$ https://orcid.org/0000-0002-6019-4762 \\ ${ }^{2}$ c/o Queensland Primary Industries Insect Collection (QDPC), Department of Agriculture and Fisheries, Queensland, Ecosciences \\ Precinct, GPO Box 267, Brisbane, Qld, 4001. "treefamily@bigpond.com; @ https://orcid.org/0000-0002-7704-7750
}

\begin{abstract}
The monotypic genus of horn-headed thrips, Eurynothrips Bagnall, had not been seen since its discovery in the early 1900's in northern Australia, and nothing is known of its biology. A second species of the genus, E. laheyi sp.n., is described from southern Queensland, inducing galls on the young terminal leaves of the small tree, Planchonella pohlmaniana [Sapotaceae].
\end{abstract}

Key words: rarity, host-plant, gall-induction, cephalic horns, generic relationships

\section{Introduction}

Early in the 1900's, from somewhere in northern Queensland, Australia, several specimens of a remarkably large thrips were collected by F.P Dodd, "the butterfly man of Kuranda" (Monteith 1991). Presumably mailed to London, these specimens are listed in the Accessions Register of the British Museum (Natural History) as "391-1902", and the dry, carded specimens were described by R.S. Bagnall (1908) as Eurynothrips, a new genus of Phlaeothripidae. The specimen labels state that the thrips came from Townsville on $14^{\text {th }}$ and $16^{\text {th }}$ July 1902 , but there is no record of how they were collected or even if they were from a plant. Differences in body size among the specimens induced Bagnall to describe two different species, the larger individuals as E. denticollis, and the smaller ones as $E$. magnicollis. A further specimen was mentioned by Bagnall (1932) labelled as "thick-legged horn-headed thrips on foliage, 28.vi.1902" and indicating that the specimen was collected by F.P. Dodd at Charters Towers. In 1965, cardmounted specimens in the Bagnall Collection were soaked off and slide-mounted into Canada balsam for detailed study (Mound 1968), and as a result E. denticollis was recognised as a synonym of the type species, E. magnicollis. Subsequently, in 1968, four specimens in a dry tube with the label "Queensland, Charters Towers, on foliage, 1901" were found at the Australian National Insect Collection, Canberra (ANIC), apparently collected by F.P. Dodd. These were slide-mounted into Canada balsam, and recognised as E. magnicollis after comparison with the type specimens. Considering the transport delays in 1901 between northern Australia and London, it is probable that all these specimens represent a single sample taken during 1901 at some locality in northern Queensland between Townsville and Charters Towers.

For over 120 years no further samples of Eurynothrips were ever recorded, despite the extensive field studies on Thysanoptera in recent decades that have resulted in the number of described thrips species in Australia increasing from about 200 in 1960 to almost 1000 now (ABRS 2021). However, in 2009 a vial of pea-shaped pods in alcohol was found in the Queensland Primary Industries Insect collection (QDPC). The label inside read 'Brimblecombe Nov 1937, Imbil, galling leaves of scrub tree' (Fig. 16). Six adult specimens were prepared onto microscope slides, although clearing the contents proved difficult - a result of being stored in ethanol for 72 years. The species was readily identifiable as Eurynothrips, but from the structure of the head we concluded that it was an undescribed species. Subsequently, in December 2014, John Lahey, a local naturalist, collected some thrips at a small forest reserve 
at Oxley, a suburb of Brisbane in southern Queensland, and asked the authors if we knew the species. These thrips were found inducing a pea pod-shaped gall on leaves of Planchonella pohlmaniana [Sapotaceae], and they proved to be the same undescribed species as that found at Imbil in 1937.

These collections emphasise the problem of defining rarity amongst thrips taxa. If a thrips is strictly host specific, then the chances of finding it are not high without knowing for what plant to search. Moreover, gall-induction is dependent on weather and season, with populations of both host plant and of thrips unpredictable and scattered. Such variation in populations is typical of many thrips taxa in Australia, and it is thus not surprising that even such spectacular thrips as members of Eurynothrips are found rarely. But a "rare species" may well be abundant at a site where its host plant is growing vigorously. At the Oxley site, with experienced local help, we were able to find several small plants of Planchonella, each supporting one or more galls formed from an apical leaf with the margins in-rolled to form a hollow tube (Figs 1-5). However, despite watching these thrips adults moving in and out of their galls, we were unable to deduce the function of the horn that occurs on the head of large individuals (of both sexes), nor of why there should be such remarkable variation in body size. The galls of many other leaf-galling thrips in Australia are invaded by kleptoparasitic and inquiline thrips species, but no such invaders were found in the Eurynothrips galls.

Field observations. Leaf galls of this thrips were observed from spring 2020 to winter 2021 in the forest reserve at Oxley. After rain in Spring, Planchonella pohlmaniana trees produced new leaves. Single adult female thrips were observed to feed on such young leaves, inducing a gall (Fig. 1). Shortly after this, additional females, and sometimes males, joined the female foundress feeding on the young leaf surface, causing the leaf to distort and twist (Fig. 2). This provided an ideal protected environment for the growing population as eggs were laid and larvae hatched. The mature gall looks like a pea pod (Figs 4-5) but the gall edges are not 'sealed'. As a result, larvae and adults could be seen to move freely around outside the gall during the day (Fig. 3).

Generally, between one and five leaf galls were formed on the young leaves at the apical end of a branch (Fig. 2). Early in summer, 2020, four young galls were collected from one terminal, also five galls from a second terminal. Each gall was measured and dissected under a stereo microscope and the contents recorded (Table 1). During dissection of the galls it was noted that the eggs appeared to be implanted in the inner thick wall of the leaf gall rather than deposited superficially as is typical of Phlaeothripidae. Six weeks later, similar dissections were repeated on samples of mature galls. In these it proved impossible to determine and count the viable eggs, because these were mixed together with empty (hatched) eggs. Remarkably, one gall housed at least 520 larvae.

TABLE 1. Eurynothrips laheyi sp.n. leaf gall data ( $\mathrm{N}=9$ galls).

\begin{tabular}{lll}
\hline Averages & Young gall & Mature gall \\
\hline Gall length & $33(17-43) \mathrm{mm}$ & $37(25-50) \mathrm{mm}$ \\
Gall width & $4(3-6) \mathrm{mm}$ & $6(4-9) \mathrm{mm}$ \\
Total adults & $2(2-3)$ & $5(2-7)$ \\
Total eggs & $60(20-100)$ & $\mathrm{n} / \mathrm{a}$ \\
Total larvae & $10(2-25)$ & $146(12-\sim 520)$ \\
\hline
\end{tabular}

During the life of the leaf galls (1-2 months), no pupae were seen sheltering inside. As the galls dry, they drop to the ground and presumably the larvae move out into the soil to pupate, waiting to emerge after rain in spring, which coincides with the host trees generating new leaves.

Eurynothrips relationships. A brief redescription of the genus Eurynothrips, based on the type specimens, was provided by Mound (1968). This referred to the "ventral spine-like projection of the frons" that Bagnall had overlooked originally on the card-mounted specimens but to which he referred in a subsequent publication (Bagnall 1932). In describing a new species below, a revised diagnosis of the genus is provided, particularly in order to compare it with the recently described Pharothrips Mound \& Wells (2020). The only species in that genus is different in its biology from the gall-inducing Eurynothrips, being considered a kleptoparasite of a gall-inducing thrips on Drypetes deplanchei [Putranjivaceae]. The larger individuals in these two genera have a remarkable tubercle ventrally on the head, but these tubercles differ between the genera in their form and site of origin on the frons. Both genera are considered members of the Liothrips-lineage of leaf-feeding Phlaeothripinae, but the range of differences indicated in Table 2 suggest they may not be closely related. 

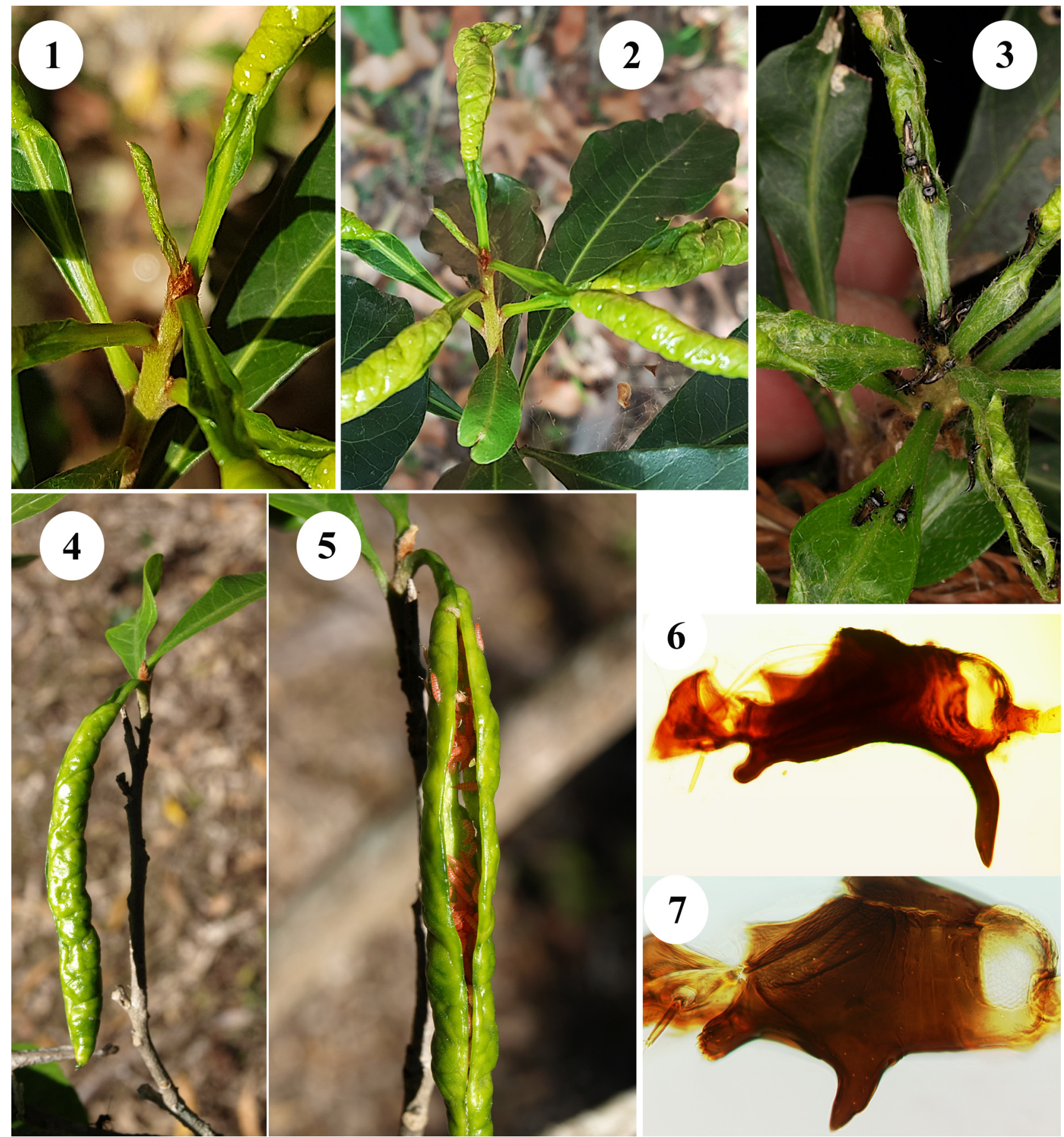

FIGURES 1-7. Eurynothrips species. Leaf galls on Planchonella pohlmaniana 1-5: (1) Young gall; (2) Galls on terminal leaves; (3) Adults wandering on gall surface; (4-5) Mature galls. (6) Head of E. magnicollis paralectotype, lateral view. (7) Head of E. laheyi paratype, lateral view.

\section{Eurynothrips Bagnall}

Eurynothrips Bagnall, 1908: 199. Type species E. magnicollis Bagnall

Generic diagnosis. Large, macropterous Phlaeothripinae; head slightly longer than wide (Figs 9, 10), with genae slightly concave, one pair of long postocular setae, compound eyes larger dorsally than ventrally; frontoclypeus posterior margin slightly swollen in small individuals but in large individuals produced into prominent tubercle over base of mouth cone; large individuals with frontoclypeus bearing prominent tubercle either between tentorial 
pits or at anterior between eyes (Figs 6, 7), small individuals lack this tubercle (Fig. 13); maxillary stylets no more than one-third of head width apart, retracted about half-way to postocular setae. Antennae 8-segmented (Fig. 11), segment III with 1 sense cone, IV with 2 sense cones; III-VII slender, VIII long and slender. Large individuals with prothorax massive, ventro-lateral to midlateral setae with pointed tubercle (Fig. 14) - large individuals with a second tubercle ventral to the first; midlateral setae arising from an almost separate sclerite (Fig. 14); notopleural sutures complete; epimera small but with seta on prominent tubercle; anteroangular setae usually longer than anteromarginals, midlateral, epimeral and posteroangular setae long and slender. Large individuals with fore femora large, bearing a tubercle on inner margin near base and another at inner apex; fore tarsal tooth longer than tarsal width (Figs 9, 10); fore legs more slender in smaller individuals. Metanotum reticulate, with pair of minute setae present, usually just anterior to median major setae (Fig. 15). Fore wing parallel sided, with 3 slender sub-basal setae, at least 30 duplicated cilia present. Prosternal basantra small in large individuals but absent in small individuals (Fig. 12); ferna irregularly sub-circular; mesopresternum reduced to pair of lateral triangles; metathoracic sternopleural sutures present. Pelta broadly triangular (Fig. 15), wider than long, campaniform sensilla usually present; tergites II-VII each with 2 pairs of sigmoid wing-retaining setae placed laterally, particularly on posterior segments; tergite IX setae S1 and S2 slender and as long as tube, tube longer than head. Male macropterous, similar to female; tergite IX setae S2 as long as setae S1; sternite VIII with no pore plate.

Species differences: The two species recognised in this genus are remarkably similar in structure. They both share all the character states indicated above, although on the few available specimens of magnicollis the minute pair of metanotal setae tend to be postero-mesad of the major setae, not antero-lateral. The only significant difference observed between the species is the position of the cephalic ventral tubercle: magnicollis - anteriorly on the frons and between the eyes (Fig. 6); laheyi - medially on the frons between the tentorial pits (Fig. 7).

TABLE 2. Character state differences between Eurynothrips and Pharothrips.

\begin{tabular}{|c|c|}
\hline Eurynothrips & Pharothrips \\
\hline Head less than 1.4 times as long as width across eyes & Head 2.0 to 2.5 times as long as width across eyes \\
\hline $\begin{array}{l}\text { Fore femur of large individuals with tubercle at inner base } \\
\text { and at inner apex }\end{array}$ & Fore femur without tubercles on inner margin \\
\hline Antennal segment III about 3.0 times as long as wide & Antennal segment III about 2.0 times as long as wide \\
\hline Antennal segment IV with 2 sense cones & Antennal segment III with 3 sense cones \\
\hline Antennal segment VIII about 0.8 as long as VII & Antennal segment VIII no more than 0.5 as long as VII \\
\hline $\begin{array}{l}\text { Fronto-clypeus posterior margin swollen over mouth-cone } \\
\text { base }\end{array}$ & Fronto-clypeus posterior margin transverse \\
\hline $\begin{array}{l}\text { Epimeral and posteroangular setal pairs longer than anten- } \\
\text { nal segment III }\end{array}$ & $\begin{array}{l}\text { Epimeral and posteroangular setal pairs only as long as } \\
\text { width of antennal segment III }\end{array}$ \\
\hline Prosternal basantra present & Prosternal basantra absent \\
\hline Prosternal ferna widely separated & Prosternal ferna median margins parallel and close together \\
\hline Metanotum reticulate & Metanotum with no sculpture \\
\hline Fore wing with 30 to 50 duplicated cilia & Fore wing with less than 15 duplicated cilia \\
\hline Fore wing sub-basal setae 150 to 300 microns long & Fore wing sub-basal setae 20 microns long \\
\hline
\end{tabular}

\section{Eurynothrips magnicollis Bagnall}

(Fig. 6)

Eurynothrips magnicollis Bagnall, 1908: 199.

Eurynothrips denticollis Bagnall, 1908: 201. Synonymised by Mound, 1968: 102

Described from "several specimens", there remain 15 slides of this species in the Natural History Museum, London, including the Lectotypes of both magnicollis and denticollis. The original description was based on the dorsal view of dry, carded specimens. No mention was made of the cephalic ventral horn, but Bagnall subsequently (1932) examined a slide-mounted head and referred to the long horn that is directed ventrally and arises on the anterior area 
of the frons between the eyes (Fig. 6). The published body lengths in the original description were from dry carded specimens; they are underestimates when compared to slide-mounted specimens.

Specimens studied. Australia, Queensland, Charters Towers, 1 male, 3 females on foliage, 1901 (F.P.Dodd) (in ANIC).
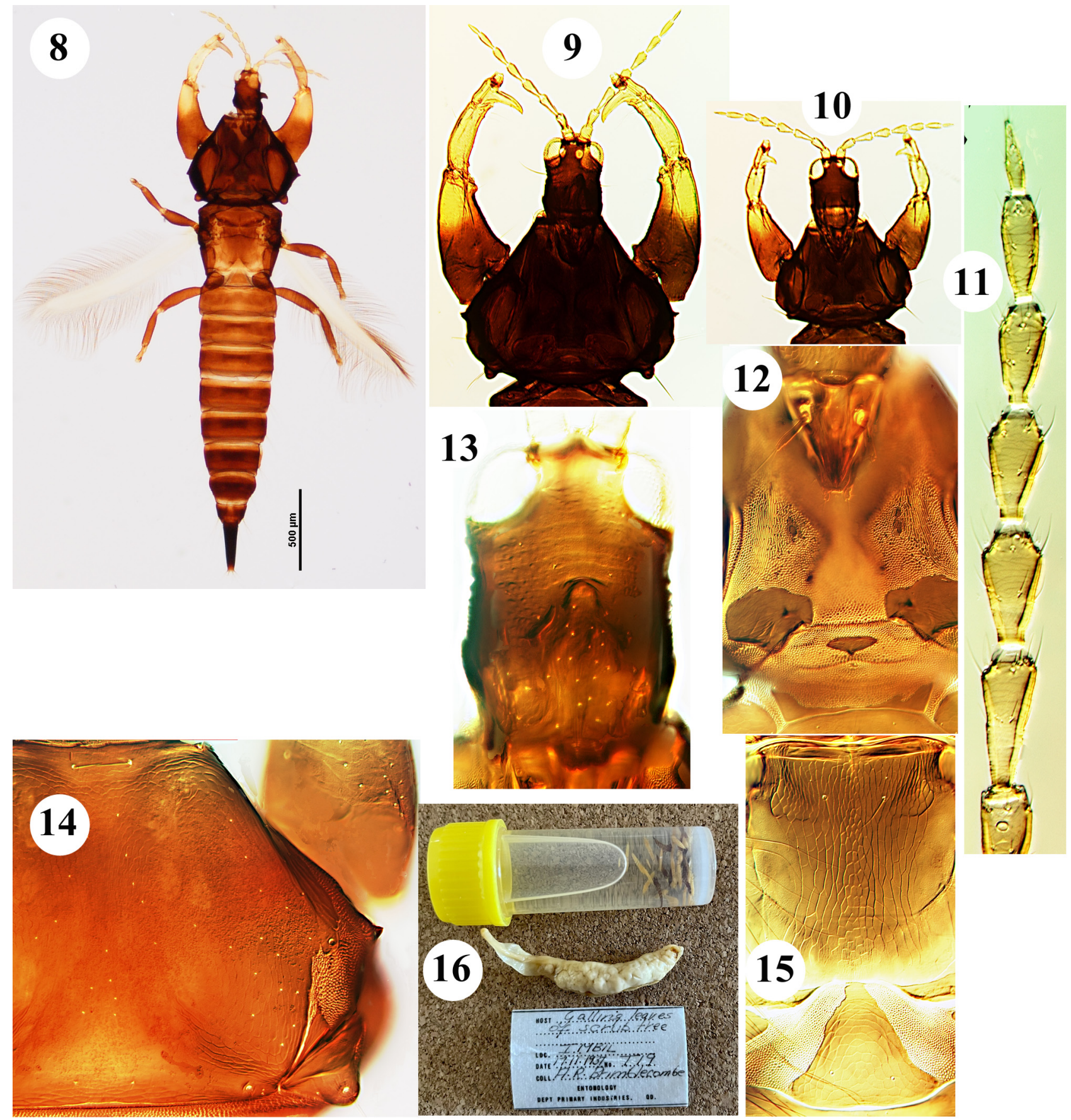

FIGURES 8-16. Eurynothrips laheyi sp.n. (8) Female; (9-10) Head and pronotum of large and small females. (11) Antenna. (12) Prosternum. (13) Holotype head ventral surface. (14) Pronotum. (15) Metanotum and pelta. (16) Specimens from Imbil (QDPC Brisbane).

\section{Eurynothrips laheyi sp.n.}

(Figs 7-15)

Female and male macropterae. Both sexes vary greatly in size between individuals (Figs 9, 10), but with no sexual dimorphism except males tend to be smaller; body and legs dark brown (Fig. 8), fore femora paler distally, fore 
tibiae and tarsi yellow; antennal segments mainly yellow with weak shading on segments II and IV-VII; major setae pale, fore wings shaded.

With the character states in the generic diagnosis; prominent tubercle on head arises ventrally between tentorial pits in large individuals (projecting laterally on right in Fig. 7 due to head rotating), reduced or absent in medium to smaller individuals including holotype (Fig. 13); frontoclypeus posterior margin forming a large emergent tubercle with rugose apex in large individuals but merely weakly swollen in smallest individuals.

Measurements (holotype female, also smallest/largest females in microns). Body length 4200 (3000-5000). Head, length 300; width across eyes 260; minimum width across genae 240; postocular setae 130 . Pronotum, length 600 (330-900); width between midlateral setae 750 (450-1100); prothorax width across fore coxae 880 (620-1300); midlateral and epimeral setae 150. Fore wing length 1500; duplicated cilia 32 (24-50); sub-basal setae 75, 125, 125. Tube length 380 (300-450). Antennal segments III-VIII length, 110, 90, 85, 80, 85, 60.

Specimens studied. Holotype female, Australia, Queensland, Brisbane, Oxley, from leaf gall on Planchonella pohlmaniana, 10.xii.2014 (John Lahey), in ANIC, Canberra.

Paratypes: 4 females 4 males taken with holotype; 4 females 2 males from same site and host plant, 16.xii.2014 (DJT 1987); 10 females 2 males from same site and host plant, 14.ii.2021 (DJT 2113); Queensland, Imbil, 5 females 7 males from pod-like gall on scrub tree, 17.xi.1937 (A. Brimlecombe), in QDPC Brisbane and ANIC, Canberra.

\section{References}

ABRS (2021) Australian Faunal Directory. Australian Biological Resources Study. Available from: https://biodiversity.org. au/afd/taxa/Thysanoptera (accessed 4 June 2021)

Bagnall, R.S. (1908) On some new genera and species of Thysanoptera. Transactions of the Natural History Society of Northumberland, 3, 183-217.

Bagnall, R.S. (1932) Brief descriptions of new Thysanoptera. XVII. Annals and Magazine of Natural History, Series 10, 10, 505-520. https://doi.org/10.1080/00222933208673602

Monteith, G. (1991) The Butterfly Man of Kuranda, Frederick Parkhurst Dodd. Queensland Museum, Brisbane, 34 pp.

Mound, L.A. (1968) A review of R.S. Bagnall's Thysanoptera collections. Bulletin of the British Museum (Natural History). Entomology Supplement, 11, 1-181. https://doi.org/10.5962/p.78614

Mound, L.A. \& Wells, A. (2020) Two new monobasic thrips genera for a gall-inducing species and its kleptoparasite (Thysanoptera, Phlaeothripinae). Zootaxa, 4759 (3), 421-426.

https://doi.org/10.11646/zootaxa.4759.3.8 